\title{
Standardization of culture age, crop growth stages and different methods of inoculation of Xanthomonas oryzae pv. oryzae, A cause bacterial leaf blight in rice (Oryza sativa L.)
}

\author{
Sonika Deep ${ }^{1}$, Durga Prasad*2 and Subhashish Sarkhel ${ }^{3}$
}

${ }^{1}$ Department of Agriculture, Jharkhand Rai University, Ranchi (Jharkhand) India

${ }^{2}$ Department of Plant Pathology, Banda University of Agriculture and Technology, Banda (U.P.) India

${ }^{3}$ Department of Plant Pathology, Dr. Kalam Agricultural College, Kishanganj (Bihar) India

(Email : thesonikadeep900@gmail.com, subhashishiari@gmail.com)

\section{ARITCLE INFO}

Received : 31.01 .2020

Revised : 15.02 .2020

Accepted : 28.02.2020

\section{KEY WORDS :}

Bacterial leaf blight, Culture age, Rice,

$\mathrm{TN}-1$. Xanthomonas oryzae pv. oryzae

*Corresponding author:

Email : dp.shubh@gmail.com

\begin{abstract}
Bacterial leaf blight caused by Xanthomonas oryzae pv. oryzae is one of the most dreaded diseases of rice across the world, particularly affecting the majority of rice growing regions of Asia. In India, rice crop is severely affected by BLB and accounts for 6- 74 per cent of estimated yield loss. Since selection of efficient screening method is important for identification of resistance against BLB, so, three investigations were conducted to find out the most efficient Xoo culture age, crop growth stage and inoculation method to evolve an efficient and reliable methodology of screening of rice genotypes for identification of resistance against BLB. In the investigations, the rice $\mathrm{TN}-1$ was used as test variety and it maintained as one hill per pot. To find out the appropriate age of Xoo culture for its successful inoculation in the host, the plants were inoculated with different ages of Xoo cultures at maximum tillering stage. The most effective inoculum age observed for BLB inoculation was 36 hours and 48 hours old culture of Xoo, both in terms of disease severity and incubation period. In case of appropriate crop growth stage for successful inoculation of Xoo, the most susceptible crop growth stage was found to be booting stage followed by panicle initiation stage. Among the different methods of inoculation; the most efficient method was clip + dip followed by clip method.
\end{abstract}

How to view point the article : Deep, Sonika, Prasad, Durga and Sarkhel, Subhashish (2020). Standardization of culture age, crop growth stages and different methods of inoculation of Xanthomonas oryzae pv. oryzae, A cause bacterial leaf blight in rice (Oryza sativa L.). Internat. J. Plant Protec., 13(1) : 30-35, DOI : 10.15740/HAS/IJPP/13.1/30-35, Copyright@ 2020: Hind Agri-Horticultural Society. 